\title{
O processo de governança na construção do Projeto de Geoparque Caminhos dos Cânions do Sul - Brasil
}

\author{
The governance process in the construction of the Caminhos dos Cânions do Sul Geopark \\ Project - Brazil
}

\begin{abstract}
Chen Lin Sung
Doutora em Geografia pela Universidade Federal da Santa Catarina (UFSC) Coordenadoria Regional de Educação (CRE) de Araranguá, Santa Catarina, Brasil sungchenlin@gmail.com

Leila Maria Vasquez Beltrão Doutora em Geografia pela Universidade Federal da Santa Catarina (UFSC) Professora do Instituto Federal Catarinense (IFC) - Campus Sombrio, Brasil

leila.beltrao@ifc.edu.br

Maurício Dalpiaz Melo

Mestre em Geografia pela Universidade Federal da Santa Catarina (UFSC) Professor do Instituto Federal de Educação, Ciência e Tecnologia de Santa Catarina (IFSC)

Campus Araranguá, Brasil $\underline{\text { mauricio.dalpiaz@ifsc.edu.br }}$

Daniel José da Silva

Doutor em Engenharia de Produção pela Universidade Federal de Santa Catarina (UFSC)

Professor Aposentado da Universidade Federal de Santa Catarina (UFSC), Brasil daniel.silva@ufsc.br

Samanta da Costa Cristiano Doutora em Ciências pela Universidade Federal do Rio Grande do Sul (UFRGS) Professora Colaboradora da Universidade Federal do Rio Grande (FURG), Brasil samantaccristiano@gmail.com
\end{abstract}

\begin{abstract}
Resumo
É possível interpretar "geoparque" como um selo de qualidade atribuído pela Global Geoparks Network (GGN)/UNESCO a territórios que promovam e protejam seu geopatrimônio, e ofereçam suporte para o desenvolvimento sustentável. Este artigo descreve o processo de governança na construção do Projeto Geoparque Caminhos dos Cânions do Sul, composto por municípios de Santa Catarina e do Rio Grande do Sul, entre 2007- 2017, visando a obtenção do "selo". A metodologia aplicada se apoiou no Modelo GATS (Governança da Água e do Território na perspectiva da Sustentabilidade), em sintonia com as diretrizes da UNESCO para candidaturas de Geoparques. O processo envolveu organizações governamentais, sociais, e de ensino, pesquisa e extensão em atividades de planejamento e na implementação de ações com o objetivo de preencher os requisitos da candidatura. Dentre os principais resultados está a criação do Consórcio Intermunicipal Caminhos dos Cânions do Sul e a disseminação do conceito de geoparque nas comunidades de sua área de abrangência. Através do processo de governança implementado, o Projeto Geoparque Caminhos dos Cânions do Sul abre perspectivas para uma nova possibilidade de desenvolvimento sustentável na região sul do Brasil.
\end{abstract}

Palavras-chave: Rede Global de Geoparques; Serra Geral; Aparados da Serra; Geopatrimônio; Modelo GATS; Desenvolvimento Sustentável; Empoderamento Social. 


\begin{abstract}
"Geopark" can be understood as a quality label awarded by the Global Geoparks Network (GGN)/UNESCO to territories that promote and protect their geoheritage, and support sustainable development. This article describes the governance process in the construction of Caminhos dos Cânions do Sul Geopark Project, composed by cities of Santa Catarina and Rio Grande do Sul, from 2007 to 2017, targeting at obtaining the Geopark label. The applied methodology was based on the GATS Model (Water and Territory Governance from the Sustainability Perspective), in line with UNESCO guidelines for Geoparks applications. The process involved governmental and social organisation, as well as teaching research institutes, with the aim of planning activities and implementing actions to fulfil the application requirements. Among the main results is the creation of the Consórcio Intermunicipal Caminhos dos Cânions do Sul and the dissemination of the concept of geopark in the communities of its coverage area. Through the governance process implemented, Caminhos dos Cânions do Sul Geopark Project opens perspectives for a new possibility of sustainable development in the southern region of Brazil.
\end{abstract}

Keywords: Global Geoparks Network; Serra Geral; Aparados da Serra; Geoheritage; GATS Model; Sustainable Development; Social Empowerment.

\title{
1. INTRODUÇÃ̃O
}

Geoparques (geoparks - original em inglês) são territórios povoados e com limites definidos, onde estratégias de proteção e promoção do geopatrimônio são combinadas com desenvolvimento local sustentável, respaldado pelas autoridades locais (ZOUROS, 2004). Tais estratégias constituem ações multidisciplinares para o desenvolvimento territorial (BRILHA, 2012).

O conceito de geoparque emergiu em meados de 1990 como resposta à necessidade de preservar e valorizar o patrimônio da Terra, suas paisagens e formações geológicas, compreendidas como testemunhas-chave da evolução do planeta Terra, nossa casa comum. Em 1991, a comunidade geológica mundial, mobilizada em torno da defesa do patrimônio geológico, realizou o I Simpósio Internacional sobre a Proteção do Patrimônio Geológico (França), que contou com a participação de especialistas de 30 países e aprovou a Declaração Internacional dos Direitos à Memória da Terra. Desde então, outros eventos vêm ocorrendo mundialmente para tratar da temática e para contribuir com o desenvolvimento de mecanismos e metodologias voltados à conservação do patrimônio geológico. Em fins da década de 1990, a Organização das Nações Unidas para a Educação, a Ciência e a Cultura (UNESCO), por meio da Divisão de Ciências da Terra, iniciaram o Programa Geoparques em resposta a este significativo movimento (RUCHKYS, 2009). A oficialização do Programa UNESCO Global Geoparks (Geoparques Globais/Mundiais) em 2015, veio reforçar o reconhecimento internacional das instituições e das comunidades sobre a importância que as Ciências da Terra têm para o bem-estar da sociedade, contribuindo para uma vida mais equilibrada e sustentável (BRILHA, 2016). 
É possível interpretar "geoparque" como um selo de qualidade atribuído pela Global Geoparks Network (GGN)/UNESCO a territórios que já funcionem como tal. Ou seja, que promovam seu patrimônio geológico para o público em geral por meio de ações educativas e de comunicação, protejam sua geodiversidade por meio de políticas de geoconservação e ofereçam suporte para o desenvolvimento socioeconômico de forma sustentável, sobretudo com iniciativas de geoturismo (UNESCO, 2014; BORBA, 2017). Dessa forma, a geoconservação, a educação e o desenvolvimento sustentável são pilares dessa estratégia de gestão de geoparques (UNESCO, 2014). Tendo em vista que em muitas sociedades a história natural, cultural e social estão intrinsecamente associadas ao contexto geológico, propostas de geoparques devem agregar valores arqueológico, ecológico, histórico e cultural (UNESCO, 2014). Cabe ressaltar que um geoparque deve apresentar patrimônio geológico singular, com geossítios de importância científica, raridade, beleza cênica e/ou valor educativo., a serem submetidos à análise por uma comissão de avaliação designada (UNESCO, 2016), respaldada em publicações científicas. Somado aos demais programas da UNESCO - Sítios do Patrimônio Mundial e Reservas da Biosfera - o Programa UNESCO Global Geoparks, forma um conjunto de instrumentos de impacto global para alcançar os Objetivos de Desenvolvimento Sustentável (ODS) da Agenda 2030 (BRILHA, 2016).

Dentre os critérios para a criação de um geoparque está o envolvimento da (s) comunidade (s), compreendido como fator crucial para o sucesso da iniciativa, dado que um geoparque exerce impacto direto no território, influenciando a população local, e porque é feito de pessoas e do diálogo dessas com os processos geológicos que ocorreram nos locais onde vivem. Pessoas que assumem o compromisso de realizar a gestão de seu território baseado no conceito holístico de proteção, educação e desenvolvimento sustentável (UNESCO, 2016).

O geoparque possibilita incluir qualquer interessado, seja individual ou institucional (ROCHA et al., 2017). Devido ao seu caráter construtivo, o geoparque também é dinâmico e complexo, pois possibilita ser adaptado a diferentes realidades, com diferentes formas de gestão, governamentais ou privadas. No entanto, o compromisso local e de participação da comunidade na construção e desenvolvimento é uma questão vital para o sucesso da proposta (BACCI et al., 2009). Nesse sentido, a UNESCO recomenda a implementação de processos desenvolvidos de baixo para cima, denominados bottom-up, e que visem a participação ativa e o empoderamento das comunidades (UNESCO, 2016).

Com vistas ao alcance desse horizonte participativo, e com foco na perspectiva da sustentabilidade do Projeto Geoparque Caminhos dos Cânions do Sul, a Agência de Desenvolvimento Regional (ADR) de Araranguá (antiga Secretaria de Desenvolvimento Regional SDR e atualmente extinta) e a Associação de Municípios do Extremo Sul Catarinense (AMESC), 
implementaram o processo de governança local, adotando modelo de governança denominado GATS (Governança da Água e do Território na perspectiva da Sustentabilidade). Este artigo tem por objetivo descrever o processo implementado. As ações descritas e os dados disponibilizados, conduzidos e sistematizados segundo critérios científicos, podem subsidiar a elaboração do Dossiê de Candidatura a Global Geopark, bem como, servir de base para a avaliação pelos especialistas da GGN/UNESCO.

\section{PROJETO GEOPARQUE CAMINHOS DOS CÂNIONS DO SUL}

Desde 2006 o Brasil vem sendo representado na GGN pelo único geoparque do país: o Geopark Araripe, localizado no sul do Ceará, com uma área aproximada de $3.440 \mathrm{~km}^{2}$. Sua candidatura foi uma iniciativa da Universidade Regional do Cariri (URCA) com apoio da Secretaria da Ciência, Tecnologia e Educação Superior (SECITE/CE) do Governo do Estado do Ceará. O baixo número de geoparques no Brasil, mesmo com geodiversidade relevante ocorre devido a diversas dificuldades e desafios encontrados, com a falta de planejamento adequado, de legislação, de educação patrimonial e de interlocução das entidades envolvidas (ROCHA et al., 2017).

Em 2012, o Projeto Geoparques do Brasil da CPRM, importante indutor da temática no país (SCHOBBENHAUS; SILVA, 2010), publicou obra contendo mais de 30 propostas de geoparques avaliadas por sua equipe técnica (SCHOBBENHAUS; SILVA, 2012). Dentre essas, está a proposta Geoparque Caminhos dos Cânions do Sul, elaborada por Godoy et al. (2011; 2012). Atualmente, existem ao menos 14 propostas em andamento no Brasil, e pode-se afirmar que o Projeto Geoparque Caminhos dos Cânions do Sul tem se destacado dentre as mais promissoras.

A área proposta para a criação do Geoparque Caminhos dos Cânions do Sul apresenta beleza cênica e geodiversidade representativa para a implantação de um geoparque (GODOY et al., 2012). Atualmente o projeto abrange sete municípios: Morro Grande, Timbé do Sul, Jacinto Machado e Praia Grande localizados em Santa Catarina (SC), e Cambará do Sul, Mampituba e Torres localizados no Rio Grande do Sul (RS), totalizando área aproximada de $2.830 \mathrm{~km}^{2}$, com 73.347 habitantes (IBGE, 2010) (Figura 1).

A área localiza-se na divisa dos estados de Santa Catarina e Rio Grande do Sul onde encontram-se uma sequência de cânions de magnífica beleza cênica, caracterizados por sua singularidade geológica e geomorfológica, delineada pelas escarpas da Serra Geral, bem como, pela diversidade cultural da população local. A geologia do território Caminhos dos Cânions do Sul é testemunha de um dos maiores eventos tectônicos ocorridos no planeta, associado à ruptura do supercontinente Gondwana há cerca de 200 milhões de anos, imprimindo na região o registro da separação dos continentes sul-americano e africano (Godoy et al., 2011; 2012). 


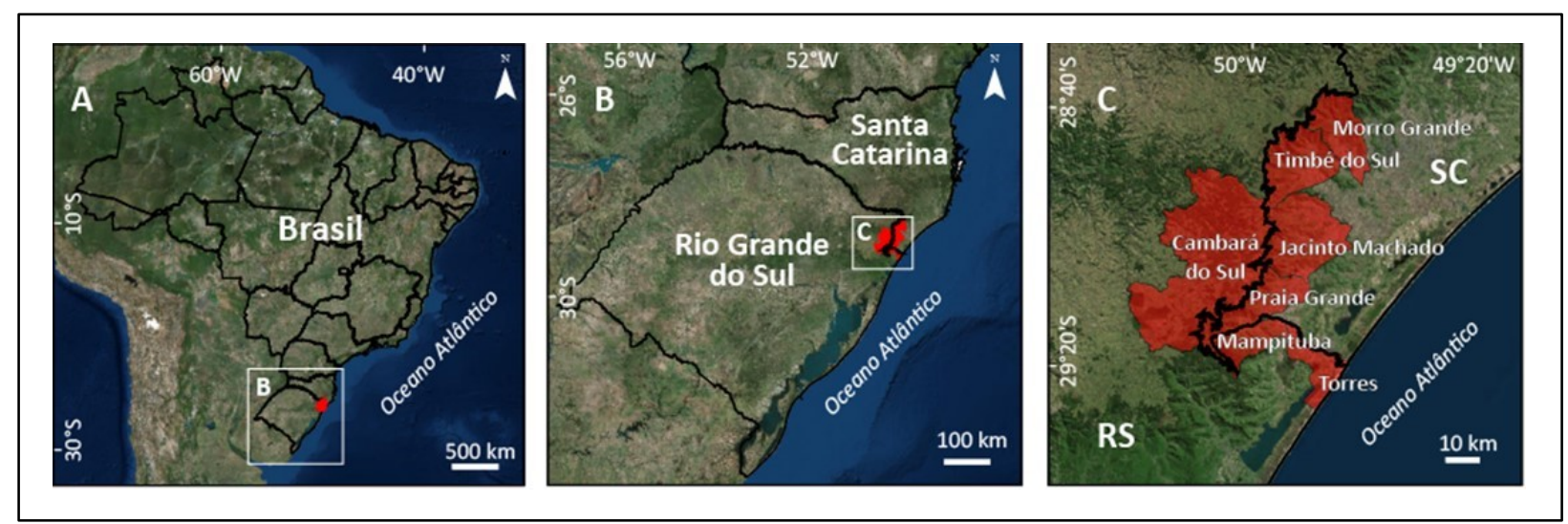

Figura 1 - Território do Projeto Geoparque Caminhos dos Cânions do Sul. A) Localização no contexto nacional; B) Interface entre RS e SC; C) Território atual da proposta de geoparque.

Fonte: Imagem: ESRI; Shapefile: IBGE.

Do litoral aos campos de cima da serra, passando pelos cortes abruptos da borda da Serra Geral, turistas de diversas regiões e origens vêm em busca de aventura, contemplação, integração com a natureza, dentre outras experiências proporcionadas pela exuberância da paisagem local (Figura 2). Na região, a riqueza natural e o mosaico de áreas protegidas se somam a heranças culturais e históricas locais (AMESC, 2016).

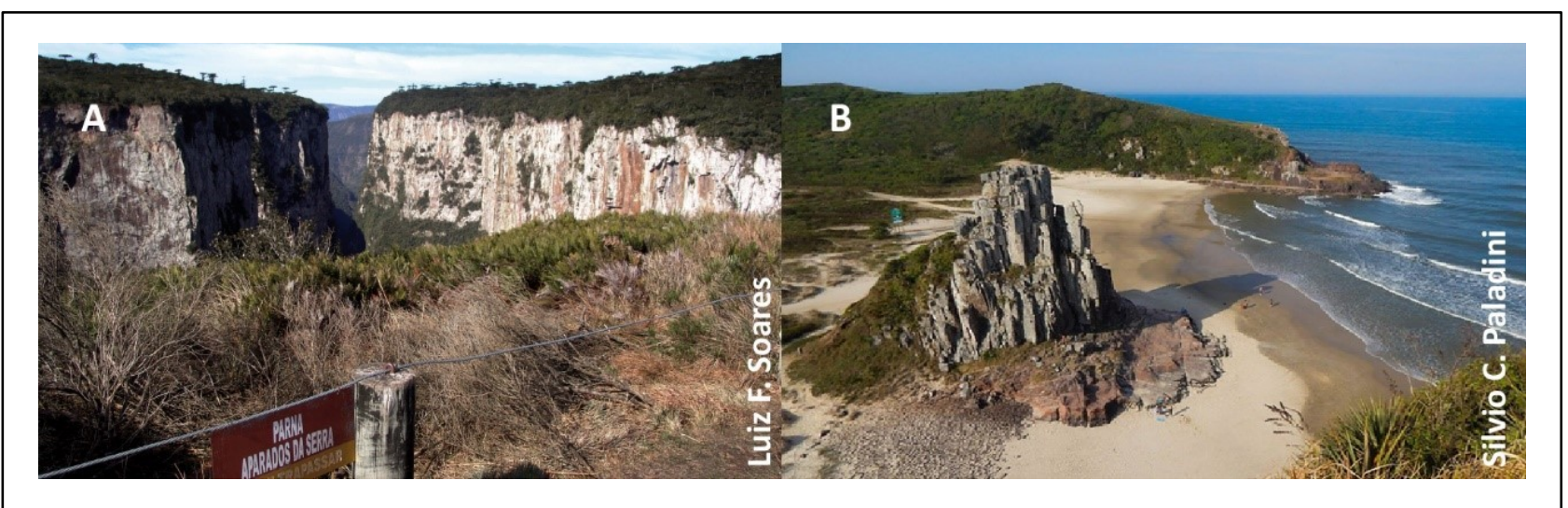

Figura 2 - Principais geossítios do Projeto Geoparque Caminhos dos Cânions do Sul. A) Cânion Itaimbezinho. Fonte: Luiz F. Soares; B) Parque da Guarita.

Fonte: Silvio Paladini.

Os primeiros moradores da região foram os índios Guarani Mbyá, Carijó, Xokleng e Kaingang. Os primeiros três grupos habitavam o litoral e o último grupo a região do planalto (BATISTA, 2017). Ambos deixaram herança linguística, presente nos nomes de municípios, cânions e rios como Cambará que significa "folha de casca rugosa", Mampituba que significa "rio de muitas curvas", Itaimbezinho que significa pedra afiada (informação oral). Posteriormente, chegaram africanos e imigrantes descendentes de açorianos, italianos e alemães. Os descendentes europeus, que constituem a grande maioria da população local, são conhecidos por sua 
hospitalidade, gastronomia, costumes e tradições (AMESC, 2016). No território também se encontram a Comunidade dos Remanescentes do Quilombo São Roque, localizada no município de Praia Grande/SC, a Aldeia Indígena Guarani MBYÁ Nhu Porã, em Torres/RS e diversas propriedades que praticam a agricultura familiar e agroecológica.

Os geoparques não constituem uma nova categoria de Unidades de Conservação (UC), nem de áreas protegidas (SCHOBBENHAUS; SILVA, 2012), contudo a existência de UC ou áreas protegidas no território candidato é necessária para receber a certificação de Geoparque (BORBA, 2017). Nesse aspecto, a área do Projeto Geoparque Caminhos dos Cânions do Sul abrange: a) dois Parques Nacionais, os Aparados da Serra (PARNAS) e a Serra Geral (PARNASG), em área contígua que envolve partes dos municípios de Jacinto Machado e Praia Grande em SC, e Cambará do Sul em RS, protegendo a biodiversidade e a geodiversidade em seus limites territoriais; b) a Reserva Biológica Estadual do Aguaí, em parte do município de Morro Grande (SC); c) uma série de UC costeiras e marinhas, no município de Torres/RS, dos quais: o Refúgio de Vida Silvestre da Ilha dos Lobos, que protege a única ilha marinha do Rio Grande do Sul, o Parque Estadual de Itapeva, que contempla um grande campo de dunas remanescente; a Área de Proteção Ambiental da Lagoa Itapeva, que engloba parte de um importante recurso hídrico; a Reserva Particular do Patrimônio Natural Recanto do Robalo, às margens do Rio Mampituba e o Parque da Guarita/José Lutzenberger. Este último, apesar de não se enquadrar nas categorias de UC brasileiras, configura uma área protegida, classificada como geossítio de relevância internacional da Proposta de Geoparque Caminhos dos Cânions do Sul de Godoy et al. (2011; 2012). Muitas UC brasileiras possuem geopatrimônio relevante, no entanto, o Sistema Nacional de Unidades de Conservação não possui abordagens para a valorização do patrimônio geológico, não existindo até então o enquadramento de geoparques em uma legislação especifica no país (NASCIMENTO et al., 2008).

\subsection{Fases do Projeto Geoparque Caminhos dos Cânions do Sul}

O Projeto Geoparque Caminhos dos Cânions do Sul tem como objetivo preparar o território, articulando, desenvolvendo e implementando ações para a candidatura ao título Geoparque Mundial da UNESCO. A primeira semente foi introduzida em 2007, pelo visionário Dr. João Matos, médico, prefeito e liderança na comunidade de Praia Grande/SC. Sua ideia foi compartilhada com autoridades locais e regional, que abraçaram o desenvolvimento do projeto. Conforme Rocha et al. (2017) é necessário planejamento estratégico para a implementação e efetivação de um geoparque, considerando-se aspectos econômicos, sociais e culturais. Todo o processo de criação de um geoparque despende de tempo e se consolida ao longo deste tempo, o que seus idealizadores devem estar cientes (ROCHA et al., 2017) e pacientes. 
O histórico do projeto pode ser compreendido em quatro fases, com três delimitações de áreas distintas (Figura 3):

i) $\quad 2007$ a 2010, com seis municípios, $3.158 \mathrm{~km}^{2}$ e estimativa de 28.573 habitantes;

ii) 2011 a 2014, com dezenove municípios, $5.750 \mathrm{~km}^{2}$ e estimativa de 251.680 habitantes (idem);

iii) 2015 a 2016, com sete municípios, $2.830 \mathrm{~km}^{2}$ e estimativa de 73.867 habitantes;

iv) a partir de 2017, quando a gestão do projeto passa a ser assumida por um Consórcio Intermunicipal, criado com o propósito amplo de promover o desenvolvimento sustentável do território.

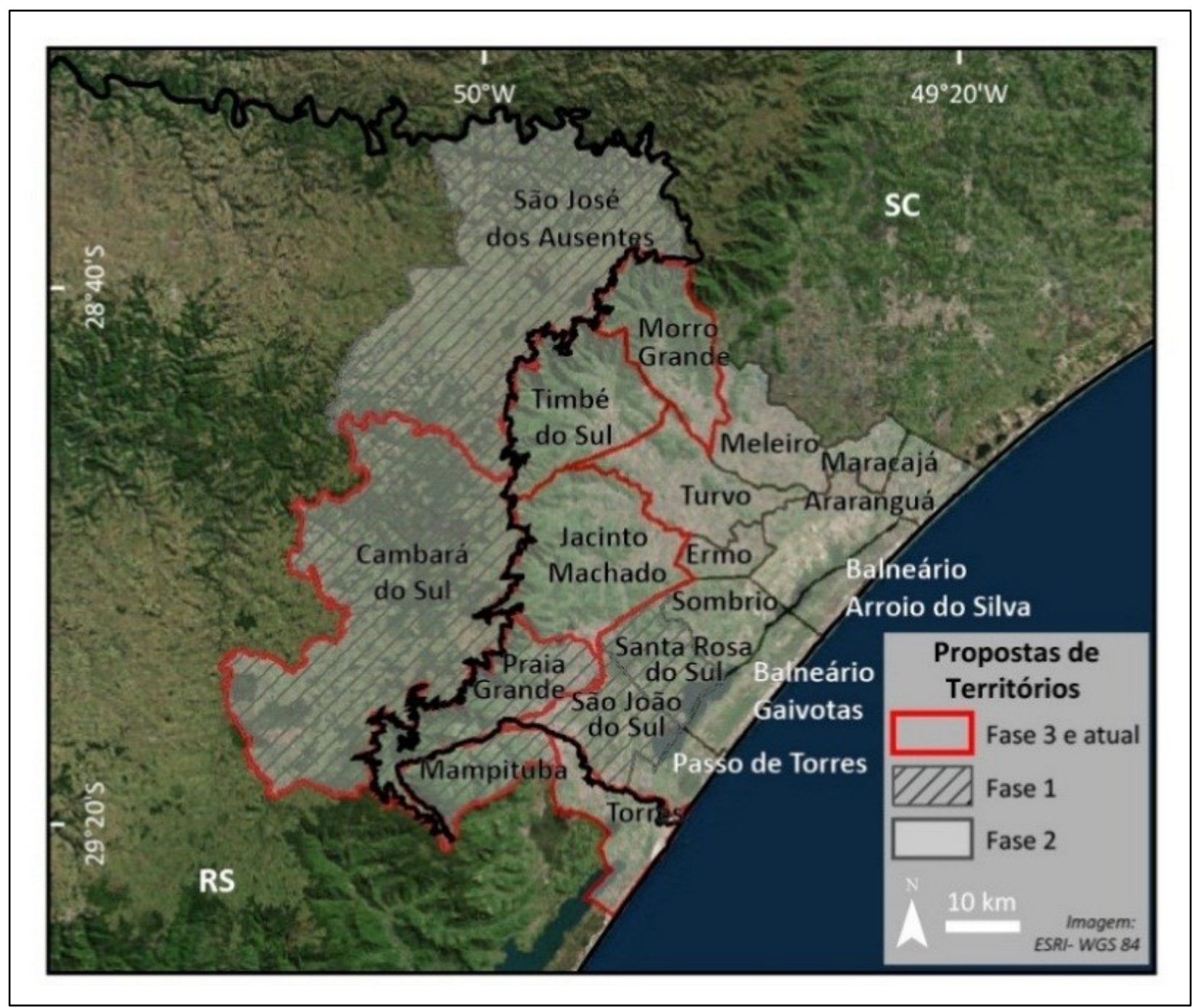

Figura 3 - Três áreas do Projeto Geoparque Caminhos dos Cânions do Sul ao longo das quatro fases de construção. Fonte: Imagem: ESRI; Shapefile: IBGE. 
A primeira fase, também primeira versão do Projeto Geoparque, denominado Cânions do Brasil, que compreende o período de 2007 a 2010, era composto de seis municípios, dos quais, três catarinenses - Praia Grande, Santa Rosa do Sul e São João do Sul - e três gaúchos - Cambará do Sul, São José dos Ausentes e Mampituba. Sob as lideranças da SDR (posterior ADR) e da AMESC, ocorreram as primeiras articulações político-institucionais e a contratação de grupo consultor, ligado à Universidade Federal do Rio Grande do Sul (UFRGS).

De acordo com Tomasi (2011), que compôs o grupo consultor, nessa primeira versão do projeto os trabalhos avançaram nas seguintes frentes: a) submissão da proposta à aprovação do Conselho do Desenvolvimento Regional do Vale do Araranguá; b) apresentação da intenção da candidatura à UNESCO Brasil, escritório Porto Alegre/RS por lideranças políticas municipais e regional; c) seminário aberto para apresentação da proposta a lideranças políticas e empresariais; d) oficina participativa de planejamento regional quando foram identificados indicadores de desenvolvimento sustentável na região; e) elaboração de um documento da candidatura; f) encaminhamento do documento para a sede da UNESCO em Paris/França. Os indicadores para o desenvolvimento sustentável relacionados ao item d) foram: a) divulgação dos hábitos culturais e da identidade regional; b) redução de emigração de jovens; c) elevação do nível de escolaridade da população em geral; d) elevação da ocupação economicamente ativa; e) redução da contaminação das águas e efluentes da região; f) aumento da oferta de alimentos orgânicos; g) aumento da produção de material científico e educacional específico e local; h) resgate, registro e divulgação dos bens culturais regionais, destacando a riqueza de etnias presentes, o patrimônio arqueológico e histórico, com destaque para o processo de colonização da região; i) resgate, registro e divulgação dos hábitos alimentares e da gastronomia regional com a promoção de produtos típicos; j) implantação de processos de qualificação e certificação de produtos regionais, avalizando processos e produtos regionais; k) aumento das oportunidades culturais para a população local; 1) aumento da participação da população nos processos de planejamento regional.

A partir de 2011, o projeto passou a ser denominado Geoparque Caminhos dos Cânions do Sul e sua área de abrangência foi ampliada de seis para 19 municípios, respaldado pelo estudo da do Projeto Geoparques do Brasil - CPRM (GODOY et al., 2011, 2012). De 2011 a 2014 (fase 2), somou-se os demais 12 municípios da região da AMESC (Passo de Torres, Balneário Arroio do Silva, Balneário Gaivota, Araranguá, Maracajá, Ermo, Timbé do Sul, Jacinto Machado, Morro Grande, Sombrio, Turvo e Meleiro) e o município de Torres no RS.

Em dezembro de 2014, em reunião de prefeitos de municípios envolvidos no projeto, realizada na Praia Grande/SC, decidiu-se pela redução da área candidata, redefinindo-a de 19 para sete municípios (Figura 1-C e Figura 3), reduzindo de $5.750 \mathrm{~km}^{2}$ para $2.830 \mathrm{~km}^{2}$ - fase 3 . Tal 
decisão levou em conta a recomendação do estudo técnico contratado na época, de que o extenso tamanho da área de abrangência do projeto poderia desfavorecer avaliação da candidatura pela GGN/UNESCO (GEODIVERSIDADE, 2013). A nova área, e atual, contempla os municípios localizados na região dos cânions dos Aparados da Serra e seu prolongamento em direção à costa atlântica gaúcha.

No período de 2011 a 2017, o Projeto Geoparque foi conduzido pela equipe técnica da ADR e da AMESC, em regime de parceria e cooperação, com a aplicação do modelo GATS na condução dos trabalhos. A descrição a que se propõe este artigo se refere mais precisamente ao processo implementado nesse período - fases 2 e 3. A partir de 2017 (fase 4) o processo passou a ser conduzido pelo Consórcio Intermunicipal Caminhos dos Cânions do Sul, um dos principais resultados do processo de governança.

\section{O MODELO GATS}

A sigla GATS significa Governança da Água e do Território na perspectiva da Sustentabilidade. O modelo GATS foi concebido pelo Grupo Transdisciplinar de Pesquisa em Governança da Água e do Território, sob a liderança do Professor Daniel José da Silva, vinculado ao Departamento de Engenharia Sanitária e Ambiental da Universidade Federal de Santa Catarina, como subsídio pedagógico e metodológico para o projeto Tecnologias Sociais para Gestão das Águas - TSGA $^{1}$ (SILVA, 2010). Se baseia na ideia da governança local e tem foco no empoderamento de pessoas/comunidades nos processos decisórios de temas que lhes dizem respeito. Tal empoderamento é assumido a partir do conhecimento do tema e da participação qualificada em processo decisório.

No sentido amplo, governança significa o processo de tomada de decisões e o processo pelo qual as decisões tomadas são implementadas, ou não (UNITED NATIONS, 2009). Opera em diversas escalas: família, bairro, município, região, país, e pode ser usada em diferentes contextos como: governança corporativa, governança internacional, governança nacional e governança local (UNITED NATIONS, 2009).

O modelo GATS é composto por cinco ciclos de aprendizagem, pensados a partir de três estratégias: cultural, fundada na valorização das experiências locais; pedagógica, centrada na perspectiva da criação de comunidades de aprendizagem visando uma participação qualificada dos envolvidos; política, com o intuito de promover o empoderamento da comunidade para a gestão local (SILVA, 2008).

\footnotetext{
${ }^{1}$ http://tsga.ufsc.br/; http://v1.tsga.ufsc.br/
} 
O Acordo Inicial abre o processo de governança. Se refere a apresentação da proposta (objetivos, resultados esperados e metodologia pedagógica) e a confirmação de participação e envolvimento no processo. Nesse ciclo, as éticas que conduzirão o processo são esclarecidas e acordadas, servindo como recurso para a mediação de conflitos e superação de dificuldades ao longo do processo. Também ocorre a identificação de demais partes interessadas e a construção de estratégias para a permanência e a ampliação da participação dos envolvidos no processo. A Avaliação e Prospecção é o ciclo que encerra o processo e diz respeito à avaliação e à consolidação de uma perspectiva de continuidade do processo participativo e da implementação das estratégias e demandas sociais apresentadas. Pode ser compreendida como uma visão de futuridade para a gestão do território.

Da estratégia cultural nasce a ideia do Diálogo e da Economia de Experiências, propondo a valorização e o resgate histórico das experiências locais. A Economia da Experiência também visa economizar erros cometidos anteriormente e potencializar iniciativas exitosas. Da estratégia pedagógica nasce a ideia da Comunidade de Aprendizagem apostando na capacidade das pessoas de aprender com o seu próprio operar, buscando conhecimento e compartilhando saberes tradicionais. Da estratégia política surge o ciclo da Estratégia de Governança como forma de oportunizar a participação da comunidade na gestão local de seu território, superando o desafio político da participação social e propondo soluções efetivas para problemas locais. Essas três estratégias representam os ciclos 2, 3 e 4 do modelo GATS. Os ciclos 1 e 5 dizem respeito ao Acordo Inicial e a Avaliação e Prospecção.

Os ciclos do GATS se referem a tempos que se sucedem ao longo do processo. Esses ciclos podem ser observados no esquema da figura 4. O esquema ilustra que cada ciclo gera uma onda, que uma vez iniciada se propaga ao longo do tempo do processo de governança. Esse movimento alimenta e potencializa os ciclos seguintes operando em sinergia no seu conjunto. Os ciclos constituem uma sucessão de tempos de aprendizagem, que ocorre tendo em vista a vivência no processo (SILVA, 2006). Apesar de haver uma sequência na implementação dos ciclos, não necessariamente se dá de forma linear. Cada interlocutor que ingressa no processo, independente do momento de sua chegada, a mobilização e a sensibilização são retomadas, suas experiências e saberes são valorizados, seus conhecimentos são acolhidos, assim como sua necessidade de se apropriar dos conhecimentos trabalhados é preenchida e suas sugestões são recebidas. Daí o motivo de cada ciclo permanecer aberto até o findar do processo. 


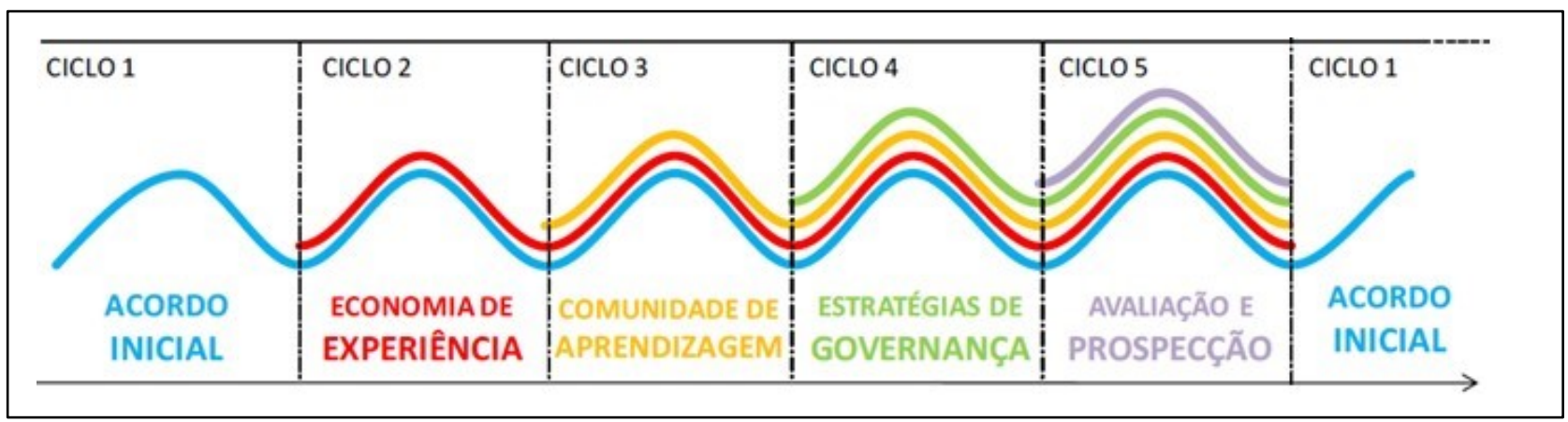

Figura 4 - Ciclos de aprendizagem. Fonte: Fernandes Neto, 2010 adaptado de TSGA, 2008.

Existe uma relação estrutural cognitiva entre os cinco ciclos do GATS. Uma vez identificados objetivos comuns, acordadas éticas de atuação conjunta e formalizada a participação, o processo caminha para conhecer as partes (valorizando vivências, promovendo trocas de experiencias e identificando preocupações, demandas e vazios de conhecimento). Identificados os vazios de conhecimento, o ciclo seguinte promove o preenchimento desses vazios, bem como, compartilha conceitos operativos relacionados ao (s) tema (s), possibilitando a participação qualificada dos envolvidos. Provido de conhecimento e ciente da realidade local, o ciclo avança para complementar o processo de empoderamento, promovendo espaço para o protagonismo das pessoas na construção de estratégias para a gestão do território, ao mesmo tempo que desenvolve/fortalece sentimento de pertencimento/afeto ao território. Por entender que toda avaliação tem potencial transformador, o ciclo da avaliação e prospecção imprime uma dimensão do compromisso da pessoa na participação no processo e na sua continuidade. O modelo GATS foi aplicado com efetividade em diversos processos de gestão social como: recursos hídricos e de saneamento; estudos para a criação de Unidade de Conservação; gestão social de prevenção do risco de desastres;etc. (e.g. FERNANDES NETO, 2010; FONSECA, 2008; HOLLANDA, 2009; MATULJA, 2009; SILVA, 2010; SUNG, 2016; TALAMINI, 2009).

\section{O PROCESSO DE GOVERNANÇA NO PROJETO GEOPARQUE CAMINHOS DOS CÂNIONS DO SUL}

Devido ao tamanho da área e grande número de municípios envolvidos no Projeto Geoparque (19 municípios, depois sete, abrangendo dois estados) foi necessário criar uma dinâmica capaz de contemplar a participação plural dos diversos segmentos sociais e governamentais. A solução adotada foi a criação de Grupos de Trabalho (GT) que interagiam com a Equipe de Coordenação (EC) e entre si, conforme ilustra a figura 5. O papel da EC, era o de implementar e conduzir o processo de governança, integrar os diversos GT e coordenar ações no âmbito do território do Projeto Geoparque Caminhos dos Cânions do Sul, sendo ações locais de responsabilidade das equipes municipais. Os GT inicialmente definidos foram (em 2012): 
Governamental, Científico-Educativo, Gerenciamento de Adversidades, Professores da Educação Básica, Iniciativa Privada do Trade de Turismo e Entidades Sociais. Ao longo do processo foram identificados projetos em curso (locais e regionais) cujos temas tivessem interface com o Projeto Geoparque Caminhos dos Cânions do Sul, tais como turismo, desenvolvimento regional, agricultura familiar, recursos naturais, educação ambiental, dentre outros. Esses projetos foram englobados nos GT e identificados como "projetos correlatos".

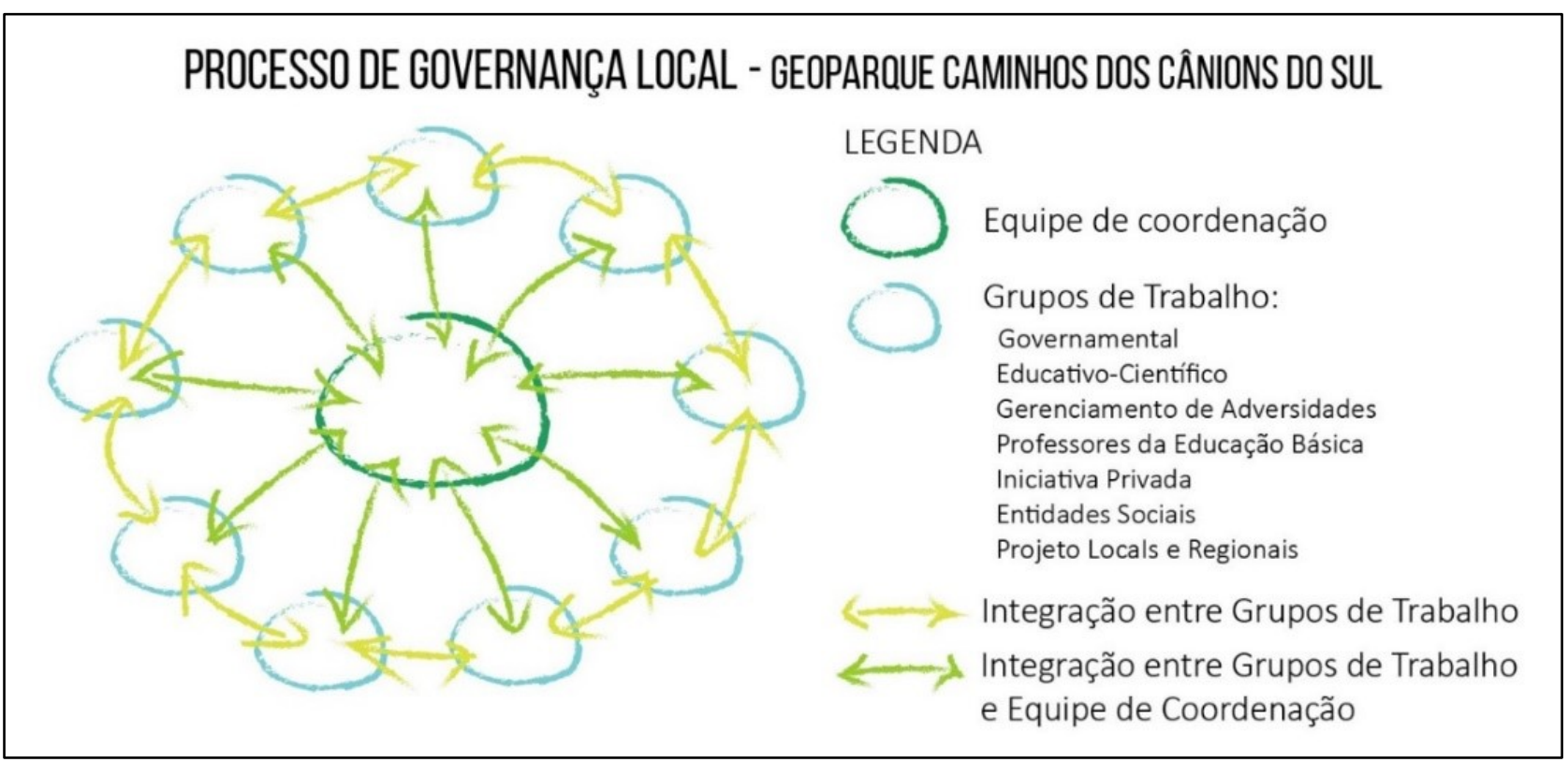

Figura 5 - Rede de integração dos atores no processo de governança do Projeto Geoparque Caminhos dos Cânions do Sul.

Fonte: Autores.

A criação dos GT levou em conta a legitimidade democrática no processo de governança e a definição dos GT levou em conta a pluralidade das representações considerando órgãos estratégicos com competência técnica e entidades civis com potencial de representação social. A composição dos GT ficou a cargo de cada município, indicando seus setores e entidades representativas.

Vale mencionar que o GT Governamental tomou a forma de Equipe Técnica do Consórcio Intermunicipal Caminhos dos Cânions do Sul (a ser apresentada mais adiante), formada por representantes indicados pelos municípios integrantes no Projeto Geoparque. O GT CientíficoEducativo evoluiu para a constituição do Comitê Educativo e Científico (CEC), composto por especialistas e pesquisadores das diferentes disciplinas relacionadas à pesquisa e disseminação do conhecimento sobre as esferas que constituem um geoparque, vindo a ser instituído na estrutura do Consórcio Intermunicipal em dezembro de 2018.

O GT Gerenciamento de Adversidades foi constituído procurando atender o compromisso assumido na Declaração de Shimabara (estabelecido na $5^{\text {a }}$ Conferência Internacional de 
Geoparques, Japão/2012), de que geoparques promovem conscientização sobre riscos associados a ameaças naturais e contribuem com estratégias de prevenção e mitigação de desastres e o GT Professores da Educação Básica visou incluir essa categoria na agenda do Projeto Geoparque Caminhos dos Cânions do Sul com dois objetivos: identificar conteúdo escolar relacionado ao tema Geologia, Geomorfologia da região trabalhado nas escolas e atender demandas de conhecimento dos professores para impulsionar esse tema por meio de palestras, oficinas e cursos de capacitação.

A formação de uma equipe multidisciplinar ativa e colaborativa, e a inter-relação entre os setores envolvidos (público e privado), é essencial no processo de criação, implementação e estruturação de um geoparque (ROCHA et al., 2017). O apoio das autoridades e o estabelecimento dessa equipe multidisciplinar, contribui no fomento de boas ideias e projetos, além de atrair investimentos que fortalecem todos os setores envolvidos (ROCHA et al., 2017).

\subsection{Acordo Inicial}

O ciclo do Acordo Inicial mobilizou e sensibilizou diversos atores sociais para a participação no processo de governança ou para a inserção do tema do geoparque em suas agendas institucionais. O processo de mobilização focou atores-chaves como representantes do Governo do Estado de SC e RS e respectivas Secretarias de governo; representantes do Ministério do Turismo; prefeitos e chefias dos respectivos órgãos municipais, em especial, de Turismo, Meio Ambiente, Educação, Agricultura e Defesa Civil; lideranças comunitárias, de entidades sociais e empresariais; chefia dos Parques Nacionais dos Aparados da Serra e Serra Geral; coordenadores ou representantes de projetos correlatos em curso no território do Projeto Geoparque Caminhos dos Cânions do Sul (implementados pelo SEBRAE, EPAGRI, Instituições de Ensino, Pesquisa e Extensão, Associações que congregam Trade Turístico, dentre outros órgãos e entidades). As ações desse ciclo consistiram em articulação política e realização de reuniões/audiências de cunho sensibilizador, propositivo e formalizador de parcerias, além de busca por apoio institucional e/ou financeiro ao Projeto Geoparque. Nessas ocasiões era apresentado o Projeto Geoparque Caminhos dos Cânions do Sul (objetivos, atrativos geoturísticos, importância para o desenvolvimento socioeconômico das comunidades locais, dimensão nacional e internacional dos geoparques, resultados esperados e importância da participação das organizações sociais e governamentais). Em seguida, buscava-se ouvir dos participantes suas visões, expectativas e inclinações em estabelecer vínculo com o projeto. Outro ponto essencial deste ciclo era o esclarecimento das éticas que conduziria o Projeto Geoparque Caminhos dos Cânions do Sul e a relação dos envolvidos no seu processo de construção: da sustentabilidade, da cooperação, do trabalho em rede e do respeito, alinhadas aos princípios das 
diretrizes da UNESCO para a candidatura a Global Geopark (Geoparque Mundial/Global). Ao final, se dava a formalização de acordos de parceria, cooperação ou apoio, conforme o caso.

Alguns resultados desse ciclo foram:

i) acordo técnico-institucional para a realização de Estudo de Inventariação de Geossítios com o Serviço Geológico do Brasil/ Superintendência de Porto Alegre;

ii) parceria com a Secretaria de Turismo, Cultura e Desporto (SOL) do Estado de Santa Catarina na contratação de serviços técnicos para a elaboração de estratégias de geoconservação para os geossítios do território catarinense e para a formatação de rotas turísticas nos municípios catarinenses envolvidos no Projeto Geoparque Caminhos dos Cânions do Sul, incluindo curso de capacitação em Turismo Rural na Agricultora Familiar (TRAF);

iii) convênio entre SDR e AMESC (Processo SDR22 0006658/2012), para operacionalização de ações, contratação de serviços e aquisição de equipamentos;

iv) parcerias institucionais com o Instituto Federal Catarinense (IFC)/Campus Sombrio e Santa Rosa do Sul, Instituto Federal de Santa Catarina (IFSC)/Campus Araranguá, Projeto TSGA (UFSC, EMBRAPA e EPAGRI), resultando em cursos de capacitação relatados no ciclo da Comunidade de Aprendizagem;

v) parceria institucional com o Curso de Tecnologias da Informação da UFSC/Campus Araranguá que resultou no desenvolvimento de ferramentas de comunicação multimídia para o Projeto Geoparque na disciplina de Sistemas Multimídias;

vi) parceria técnico-científico com o Laboratório GTHIDRO do Departamento de Engenharia Sanitária e Ambiental/UFSC para assessoria na aplicação do modelo GATS de governança local.

\subsection{Economia da Experiência}

O foco central desse ciclo é a valorização e o resgate de experiências, saberes e conhecimentos locais ou externos, buscando potencializar iniciativas de êxito e aprender com os erros ocorridos. As ações desse ciclo ocorreram por meio de encontros (reuniões, oficinas, visitas) e de levantamento de experiências de outros geoparques, bem como, de projetos envolvendo boas práticas de gestão territorial compartilhada e desenvolvimento sustentável. A estratégia mediadora utilizada nos encontros foi o diálogo e focou nas experiências locais relacionadas ao turismo sustentável, práticas de educação ambiental, gestão sustentável dos recursos naturais, incentivo a agricultura ecológica e familiar, gestão do risco de desastres (especialmente associado a extremos 
climáticos), participação em redes colaborativas, conhecimento do território, demandas de cursos de capacitação, dentre outros temas.

Os participantes também eram incentivados a avaliar as capacidades socioinstitucionais de seus municípios na consecução do Projeto Geoparque, possibilitando um diagnóstico da realidade como referência de partida para a formulação de estratégias de gestão do território. As rodas de diálogo tiveram grande contribuição para compartilhar experiências exitosas, bem como, ampliar a visão da equipe de coordenação acerca das realidades locais. Da mesma forma, o conhecimento e os saberes locais também serviram para enriquecer trabalhos técnicos e científicos voltados para o território do Projeto Geoparque Caminhos dos Cânions do Sul. Um exemplo foi uma oficina realizada para coleta de dados adicionais sobre os geossítios inventariados pela CPRM. A participação de guias, condutores e agentes municipais preencheu lacunas de dados mais detalhados, como: status da propriedade, condição de acesso, melhor ponto de contemplação, aspectos relacionados a riscos e vulnerabilidades, dentre outras informações pertinentes.

Visando o preenchimento do Formulário de Autoavaliação da UNESCO para geoparques candidatos, a equipe de coordenação elaborou formulário direcionado ao GT Governamental para coleta de dados específicos sobre áreas verdes e áreas de proteção (reservas ecológicas, unidades de conservação, comunidades indígenas, quilombolas, sambaquis e outros); pontos turísticos (pontos de contemplação de paisagens cênicas, sítios geológicos, arqueológicos e outros); estrutura turística dos municípios (hotelaria, gastronomia, acessos, logística, calendário festivo, meios de divulgação, trilhas, mapas); mecanismos de informação e divulgação; práticas/ programas de educação ambiental (voltados para a conservação de recursos naturais e valorização da cultura e da história local); práticas de geoturismo (com base no conceito explicitado na Carta de Arouca - Arouca, 2011); principais atividades econômicas e empreendimentos turísticos, em especial, os voltados a pequenos negócios, artesanato e agricultura familiar; projetos e políticas voltadas à economia sustentável, existência de Planos de Turismo e de Planos de Desenvolvimento de âmbito municipal. O Formulário de Auto-Avaliação (Self-Assessment Form - versão 2012) foi traduzido pela equipe de coordenação e compartilhado amplamente, bem como, o documento intitulado Diretrizes e Critérios para Geoparques Nacionais que buscam assistência da UNESCO para ingressar na GGN (Guidelines and Criteria for Nacional Geoparks seeking UNESCO's assistance to join the Global Geoparks Network - GGN /versões 2010 e 2014).

O conhecimento com a experiência de geoparques constituídos foi promovido por especialistas que atuam em geoparques mundiais em visita no território (e.g. Arthur Sá e José Brilha). Com o mesmo propósito, membros do GT Educativo e Científico, visitaram o Geopark Grutas Del Palácio/Uruguai (nov/2014) e o Geopark Araripe/Ceará (out/2015). Esta última, 
financiada por projeto submetido pelo IFSC/Campus Araranguá ao Edital DEB/CAPES 055/2012 Projeto Novos Talentos.

\subsection{Comunidade de Aprendizagem}

No Ciclo da Comunidade de Aprendizagem foram realizados cursos de capacitação abertos à comunidade, cujos temas foram definidos com base em demandas e lacunas de conhecimento identificadas no ciclo anterior. O programa de capacitação foi delineado no bojo do Comitê Educativo-Científico (CEC), cujos cursos foram realizados por meio de parcerias técnicoinstitucionais com instituições de ensino, pesquisa e extensão que atuam na região, com os seguintes temas: Aspectos da Geologia e da Geomorfologia da Região Aspirante ao Geoparque Caminhos dos Cânions do Sul; Geoconservação, Geoturismo e Geoparques; Geodiversidade, Geoconservação, Geoturismo e Geoeducação no contexto de Geoparques; Agricultora Familiar e Turismo Rural; Condutor Ambiental Local; Turismo Rural na Agricultura Familiar - TRAF. Nesse ciclo também ocorreram atividades de educação ambiental em escolas e saídas de campo para (re)conhecimento do território.

\subsection{Estratégia de Governança}

No ciclo da Estratégia de Governança foram definidas as seguintes macroações: definição da marca nominativa e criação de sínteses visuais para a identificação do Projeto Geoparque Caminhos dos Cânions do Sul; disseminação do projeto e divulgação das ações ocorridas para o conhecimento da sociedade; redefinição da área do projeto; criação de um consórcio intermunicipal como entidade gestora do território; elaboração de Plano de Ação com vistas à candidatura; captação de recurso financeiro para execução das ações; formalização e institucionalização do Comitê Educativo e Científico.

\subsection{Avaliação e Prospecção}

De fato, no modelo GATS a avaliação das ações é processual. A finalidade desse ciclo é avaliar o todo do processo implementado e prospectar a continuidade da ação participativa do grupo numa perspectiva de futuridade. Considerando o período de 2007 a 2017, avaliou-se que a construção de um projeto geoparque nos termos da UNESCO/GGN, envolve intensa mobilização política, social e institucional, participação qualificada de atores plurais, tempo para o amadurecimento da ideia e, nesse sentido, respeito aos diferentes tempos (timings) dos atores envolvidos (pessoas, instituições e municípios), além dos recursos disponíveis (humano, material e 
financeiro). Dessa forma, o período de dez anos se justifica, levando em conta que, apesar da unicidade do patrimônio geológico, a participação de dois estados e sete municípios, três conformações regionais distintas (região do extremo sul de Santa Catarina, litoral norte do Rio Grande do Sul e serra gaúcha), apresentando diferentes realidades sociais, culturais, econômicas, conforme apresentado no quadro 1, são aspectos que demandaram tempo para serem equacionados para a formatação de um território comum. Sem mencionar o tema geoparque não ser popularmente conhecido no Brasil.

Quadro 1 - Dados dos municípios que compõem o território atual do Projeto Geoparque Caminhos dos Cânions do Sul.

\begin{tabular}{cccccccc}
\hline Municípios & $\begin{array}{c}\text { Ano de } \\
\text { criação }\end{array}$ & Área $\left(\mathbf{k m}^{2}\right)$ & $\begin{array}{c}\text { Altitude } \\
(\mathbf{m})\end{array}$ & População & $\begin{array}{c}\text { DD* } \\
\left(\mathbf{h a b} / \mathbf{k m}^{2}\right)\end{array}$ & $\begin{array}{c}\text { IDHM** } \\
\text { Per capita (R\$) }\end{array}$ \\
\hline Morro Grande/SC & 1992 & 258,184 & 90 & 2.918 & 11,19 & 0,701 & $62.079,44$ \\
Timbé do Sul/SC & 1967 & 330,089 & 127 & 5.379 & 16,08 & 0,720 & $16.829,50$ \\
Jacinto Machado/SC & 1958 & 431,379 & 43 & 10.573 & 24,59 & 0,716 & $22.875,17$ \\
Praia Grande/SC & 1958 & 284,163 & 44 & 7.367 & 25,58 & 0,718 & $17.408,68$ \\
Cambará do Sul/RS & 1963 & $1.208,647$ & 1.023 & 6.687 & 5,41 & 0,697 & $19.572,38$ \\
Mampituba/ RS & 1995 & 157,848 & 37 & 3.081 & 19,02 & 0,649 & $15.685,80$ \\
Torres/RS & 1878 & 160,565 & 17 & 37.342 & 215,84 & 0,762 & $26.349,96$
\end{tabular}

*DD: Densidade Demográfica; **IDHM: Índice de Desenvolvimento Humano Municipal. ***PIB: Produto Interno Bruto.

Fonte: IBGE (2010); Atlas Brasil (2010).

Os dados do quadro 1 mostram que as áreas dos municípios envolvidos no Projeto Geoparque Caminhos dos Cânions do Sul variam de 1.208,647 km² a 157,848 km², entre o de maior e o de menor extensão, em diferença de mais de $1.000 \mathrm{~km}^{2}$. Percorrer todo esse território foi um grande desafio nas fases de sensibilização e mobilização local, tendo em vista suas localizações entre $17 \mathrm{~m}$ a mais de $1.200 \mathrm{~m}$ de altitude, muitas vezes, em vias de acesso não pavimentadas e em estado precário. A participação de 2 estados, de cujas capitais estão a mais de $200 \mathrm{~km}$ da área do projeto, em direção ao norte e ao sul, também representou dificuldade na mobilização e sensibilização das esferas estaduais. As densidades demográficas dos municípios são muito variadas, sendo que, do mais ao menos denso $\left(215,84 \mathrm{hab} / \mathrm{km}^{2}-5,41 \mathrm{hab} / \mathrm{km}^{2}\right)$, há diferença considerável, implicando na quantidade e qualidade de oferta de serviços turísticos. Do ponto de vista da governança, o início do processo necessitou tempo para o alinhamento e ajuste das diferenças que implicavam no equilíbrio do processo participativo.

Outro grande desafio avaliado foi a sobreposição de territórios na área de abrangência do Projeto Geoparque Caminhos dos Cânions do Sul (Figura 6), como são os casos das Unidades de Conservação, federal e estadual (PARNAAP, PARNASG, Parque Estadual da Itapeva/RS) e áreas 
de comunidades tradicionais (aldeia indígena Nhu Porã e quilombo Pedra Branca), e mesmo territórios que não constituem áreas físicas como o espaço de atuação dos projetos de temas correlatos com os quais o Projeto Geoparque Caminhos dos Cânions do Sul estabeleceu vínculo, seja de parceria, cooperação ou apoio. Para lidar com essa questão, o GATS contribuiu desde seu ciclo inicial, quando foram explicitadas entre os participantes as éticas que conduziriam o processo de governança, dentre elas, do respeito ao espaço de cada ente participante.

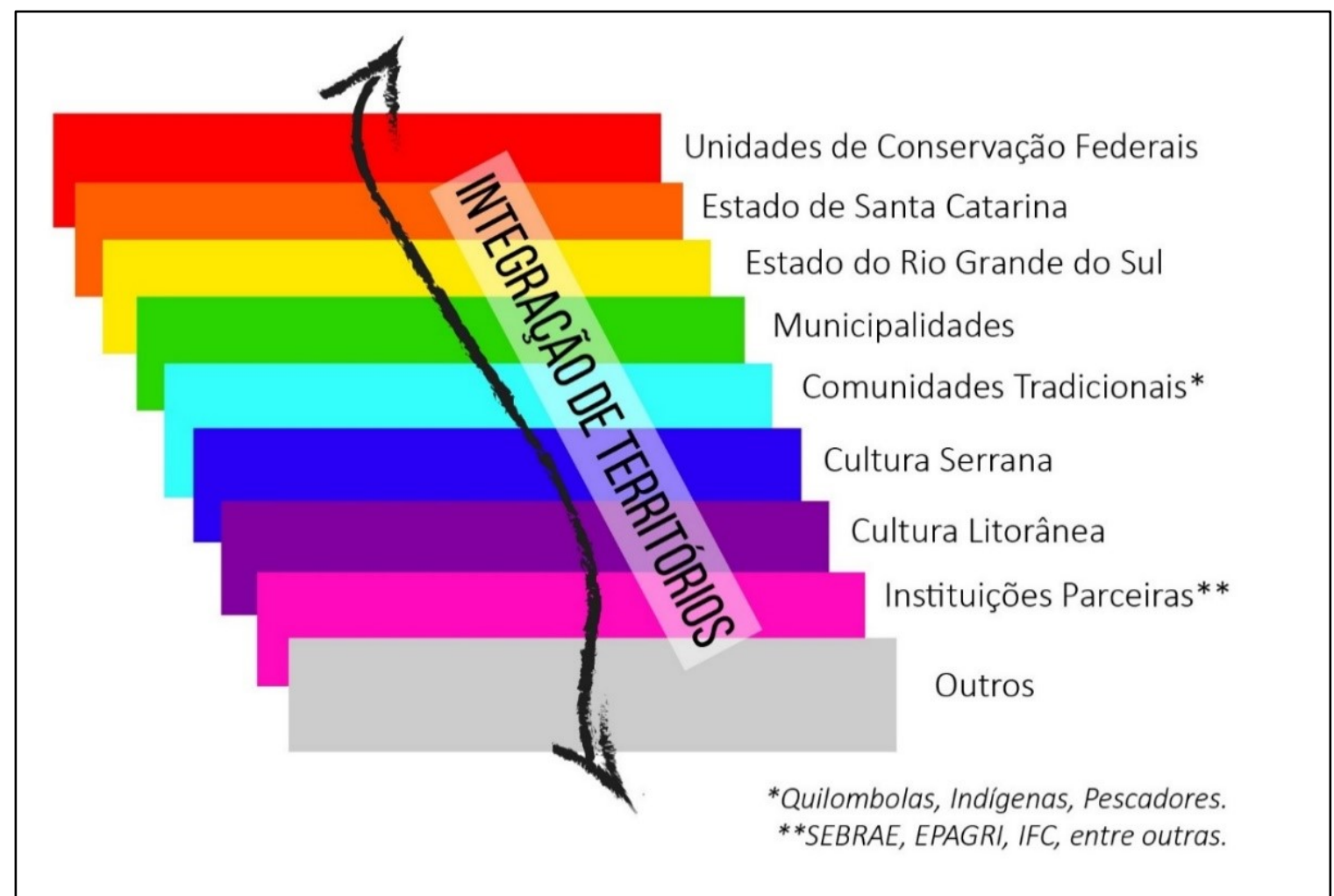

Figura 6 - Esquema da sobreposição dos territórios do Projeto Geoparque Caminhos dos Cânions do Sul. Fonte: Autores.

Merece avaliação também a criação do Consórcio Intermunicipal Caminhos dos Cânions do Sul como instrumento de gestão do território. Do ponto de vista jurídico-institucional a opção foi considerada acertada. Contudo, do ponto de vista da inclusão da sociedade na gestão do território geoparque, há arranjos a serem realizados. A falta de regulamentação sobre criação e para a implementação dos geoparques no país configura uma limitação para a formalização jurídica (CUNHA; MUNHOZ, 2017).

Por fim, entende-se que a própria elaboração desse manuscrito por membros do Comitê Educativo e Científico do Projeto Geoparque Caminhos dos Cânions do Sul configura uma ferramenta de avaliação e prospecção, procurando tornar pública as ações desenvolvidas no período mencionado. Desta forma, evidencia-se a importância da essência participativa e cooperativa, agregando conhecimento científico e saberes locais na construção desse projeto comum que envolve 
todos habitantes do território e demais pessoas ligadas pelo sentimento de pertencimento ao patrimônio natural da região. A concepção em rede da comunidade global de geoparques pode se constituir como uma poderosa ferramenta para a preservação do patrimônio material e imaterial através da geoeducação, contribuindo efetivamente para a sustentabilidade por viabilizar o alcance de novos padrões para o uso antrópico dos territórios (BACCI et al., 2009).

\section{CONSIDERAÇÕES FINAIS}

No contexto do Projeto Geoparque Caminhos dos Cânions do Sul, o GATS implementou: processos de mobilização, sensibilização e participação socioinstitucional; articulou ação setorial integrada; introduziu o tema geoparque nas agendas institucionais de parceiros e apoiadores; disseminou o conceito de geoparque e termos correlatos no território; promoveu relacionamento cooperativo com projetos correlatos que vinham sendo desenvolvidos no território; criou espaço para o compartilhamento de experiências e boas práticas; promoveu a participação qualificada, capacitando pessoas e incentivando o protagonismo social; e promoveu a construção coletiva de estratégias de gestão local com foco na sustentabilidade e na valorização dos bens comuns. Dessa forma, entende-se que o modelo GATS se mostrou efetivo em alcançar o que a UNESCO e a GGN preconizam em termos de engajamento local e empoderamento da comunidade na construção de um geoparque. Ou seja, o GATS configura uma ferramenta efetiva para a implementação do processo de governança e pode ser replicado em outros territórios do país que também buscam o título de Global Geopark, viabilizando ações multidisciplinares para o desenvolvimento territorial sustentável.

O processo de governança local buscou estimular o sentimento de pertencimento nos envolvidos, além de levar às pessoas uma mensagem de valorização da cultura e do patrimônio natural local, de conhecimento e de como operar em conjunto (cooperar). Baseado no processo de governança implementado, o Projeto Geoparque Caminhos dos Cânions do Sul vai se consolidando aos poucos como uma nova possibilidade de desenvolvimento sustentável, com geração de renda e emprego na região sul do Brasil.

Apesar do requisito primário para a criação de um geoparque ser a presença de geopatrimônio com relevância científica internacional (UNESCO, 2016), as condições para se obter a chancela vão muito além. Isso porque, para a implementação e a manutenção de um geoparque é preciso concretizar ações de geoconservação, geoturismo e geoeducação, além de promover a riqueza cultural e a história local. Essas ações são realizadas por pessoas e envolve compromisso com o passado, o presente e o futuro do local. Assim, geoparque não se trata apenas de uma área física, delimitada, mas de pessoas que fazem a gestão de seu território, comprometidas com a 
disseminação das geociências e o desenvolvimento socioeconômico local, na perspectiva da sustentabilidade intergeracional.

\section{AGRADECIMENTOS}

Agradecemos ao visionário Dr. João Matos, ex-prefeito Praia Grande/SC, que trouxe a ideia de geoparque para a região. Ao Consórcio Intermunicipal Caminhos dos Cânions do Sul e demais colegas do Comitê Educativo e Científico. À AMESC pela co-liderança na equipe de coordenação do projeto entre 2011 e 2017, em especial à Cris (in memorium), pessoa fundamental nessa construção. À Coordenação de Aperfeiçoamento de Pessoal de Nível Superior pela bolsa do Programa Nacional de Pós-Doutorado (CAPES/PNPD) concedida à última autora.

\section{REFERÊNCIAS}

AMESC. Associação dos Municípios do Extremo Sul Catarinense. A história da região do Extremo Sul Catarinense, Santa Catarina, 2016. Disponível em: https://www.amesc.com.br/cms/pagina/ver/codMapaItem/71130. Acesso em: 05 mar. 2018.

ATLAS BRASIL. Atlas do Desenvolvimento Humano no Brasil. Índice de Desenvolvimento Humano Municipal (IDHM) 2010, 2010. Disponível em: http://www.atlasbrasil.org.br/. Acesso em: 18 mai. 2018.

BACCI, D. L. C.; PIRANHA, J. M.; BOGGIANI, P. C.; LAMA, E. A. Geoparque - Estratégia de Geoconservação e Projetos Educacionais. Revista do Instituto de Geociências - USP, São Paulo, v. 5, Publ. espec. p. 7-15, 2009.

BORBA, A. W. Um Geopark na região de Caçapava do Sul (RS, Brasil): uma discussão sobre viabilidade e abrangência territorial. Geographia Meridionalis, Pelotas, v. 3, n. 1, p. 104-133, 2017.

BRILHA, J. A Rede Global de Geoparques Nacionais: um instrumento para a promoção internacional da geoconservação. In: SCHOBBENHAUS, C.; SILVA, C. R. Geoparques do Brasil - Propostas. CPRM, 2012. cap. 2, p. 29-37.

BRILHA, J. UNESCO e Programa Internacional Geociências e Geoparques. São Paulo, 2016. Disponível em: http://www.igc.usp.br/index.php?id=977. Acesso em: 11 nov. 2017.

CUNHA, D. A.; MUNHOZ, E. A. P. Geoparque x parque nacional: um olhar jurídico. Âmbito Jurídico, Rio Grande, v. 20, n. 164, p. 4, 2017.

FERNANDES NETO, J. A. S. Modelo Urubici de governança da água e do território: Uma tecnologia social a serviço do desenvolvimento sustentável local. 2010. $235 \mathrm{f}$. Tese (Doutorado em Engenharia Ambiental) - Programa de Pós-Graduação em Engenharia Ambiental, Universidade Federal de Santa Catarina, Florianópolis, 2010.

FONSECA, M. Estratégias de Governança da Água para a proteção da Zona de Recarga Direta do Aquifero Guarani na bacia do rio Urubici. 2008. 77 f. Monografia (Trabalho de Graduação em Engenharia Sanitária e Ambiental) - Universidade Federal de Santa Catarina, Florianópolis, 2008. 
GEODIVERSIDADE. Geodiversidade Soluções Geológicas Ltda. Projeto Geoparque Caminhos dos Cânions do Sul: Diagnóstico do território e recomendações para a candidatura à Global Geoparks Network - GGN. Relatório Técnico, Araranguá, AMESC, 2013.

GODOY, M.; BINOTTO, R.B.; WILDNER, W. Geoparque Caminho dos Cânions do Sul Proposta. Relatório Técnico, Projeto Geoparques, Rio de Janeiro, CPRM, 2011, 110p.

GODOY, M.; BINOTTO, R.B.; WILDNER, W. Geoparque Caminho dos Cânions do Sul (RS/SC). In: SCHOBBENHAUS, C.; SILVA, C. R. Geoparques do Brasil - Propostas. CPRM, 2012. cap. 13, p. 29-37.

HOLLANDA, C. L. Estratégias de Governança em Resíduos Sólidos no Município de UrubiciSC. 2009. 100 f. Monografia (Trabalho de Graduação em Engenharia Sanitária e Ambiental) Universidade Federal de Santa Catarina, Florianópolis, 2009.

IBGE - Instituto Brasileiro de Geografia e Estatística. Censo 2010. Disponível em: https://censo2010.ibge.gov.br/apps/atlas/2010. Acesso em: 01 ago. 2018.

MAtulja, A. Construção de um Termo de Referência para o Plano Municipal de Saneamento de Urubici-SC a partir de um Modelo de Governança. 2009. 109 f. Monografia (Trabalho de Graduação em Engenharia Sanitária e Ambiental) - Universidade Federal de Santa Catarina, Florianópolis, 2009.

NASCIMENTO, M. A. L.; RUCHKYS, U. A.; MANTESSO-NETO, V. Geodiversidade, Geoconservação e Geoturismo: trinômio importante para a proteção do patrimônio geológico. 1. ed. São Paulo: Sociedade Brasileira de Geologia, 2008. 82 p.

ROCHA, L. C.; FERREIRA, A C.; FIGUEIREDO, M. A. A Rede Global de Geoparques e os desafios da integração dos Geoparques Brasileiros. Caderno de Geografia, Belo Horizonte, v. 27 , n. 2, p. $271-292,2017$.

RUCHKYS, U.A. Geoparques e a Musealização do Território: um Estudo Sobre o Quadrilátero Ferrífero. Revista do Instituto de Geociências - USP, São Paulo, v. 5, p. 35-46, 2009.

SCHOBBENHAUS, C.; SILVA, C.R. Geoparques do Brasil: Propostas. Rio de Janeiro: CPRM, 2012. 750p.

SCHOBBEnHAUS, C.; SILVA, C. R. O papel indutor do Serviço Geológico do Brasil na criação de geoparques. 2010.2010 Disponível http://sigep.cprm.gov.br/destaques/Schobbenhaus_Silva_2010.pdf. Acesso em: 25 jan. 2018.

SILVA, D. J. Desafios sociais da gestão integrada de bacias hidrográficas: uma introdução ao conceito de governança da água. In: Congrès de 1'ACFAS, 74,. 2006, Montreal. Anais... Montreal, 2007, p. 1-12.

SILVA, D. J.; ARNESEN, A. S.; ARRUDA, L. B.; CURTARELLI, M. P.; FERNANDES NETO, J. A. S.; FURTADO, D. F. C.; GENOFRE, F. T.; MATUlJA, A.; SILVA, J. S.; SMITH, R. E. Modelo de Governança da Água e do Território para a Zona de Recarga Direta do Aquífero Guarani, no município de Urubici/SC. In: II Congresso Aquífero Guarani, 2008, Anais... Ribeirão Preto, 2008, p. 1 - 5. 
SILVA, J. S. Instrumentos de Governança da Água nas bacias hidrográficas do município de Urubici, SC, no contexto das tecnologias sociais. 2010. 176 f. Dissertação (Mestrado em Engenharia Ambiental) - Programa de Pós-Graduação em Engenharia Ambiental, Universidade Federal de Santa Catarina, Florianópolis, 2010.

SUNG, C. L. Construção social de prevenção, mitigação e proteção frente a eventos climáticos extremos com atores locais: uma experiência no município de Araranguá/SC. 2016. 1185 f. Tese (Doutorado em Geografia) - Programa de Pós-Graduação em Geografia, Centro de Filosofia e Ciências Humanas, Universidade Federal de Santa Catarina, Florianópolis, 2016.

TAlAMini, G. C. Avaliação de Processo de Governança da Água Associado à Tecnologias Sociais no Município de Urubici - SC no Contexto do Projeto TSGA. 2009. 86 f. Monografia (Trabalho de Graduação em Engenharia Sanitária e Ambiental) - Universidade Federal de Santa Catarina, Florianópolis, 2009.

TOMASI, R. M. Desenvolvimento Regional Sustentável com Base no Turismo: A proposta do Geoparque dos Canyons do Brasil. 2011. 115 f. Dissertação (Mestrado Administração) - Escola de Administração. Programa de Pós-Graduação em Administração, Universidade Federal do Rio Grande do Sul, Porto Alegre, 2011.

UNESCO. Organização das Nações Unidas para a Educação, a Ciência e a Cultura. Guidelines and Criteria for National Geoparks seeking UNESCO's assistance to join the Global Geoparks Network (GGN). França, 2014. Disponível http://www.unesco.org/new/fileadmin/MULTIMEDIA/HQ/SC/pdf/Geoparks_Guidelines_Jan2014. pdf. Acesso em: 19 fev. 2017.

UNESCO. Organização das Nações Unidas para a Educação, a Ciência e a Cultura. Celebrating Earth Heritage, Sustaining local Communities. França, 2016. Disponível em:http://unesdoc.unesco.org/images/0024/002436/243650e.pdf. Acesso em: 11 nov.2017.

UNITED NATIONS. What Is Good Governance? Economic and Social Commission for Asia and the Pacific (ESCAP), 2009. Disponível em: http://www.unescap.org/pdd/prs/ProjectActivities/Ongoing/gg/governance.asp. Acesso em: 15 jul. 2019.

ZOUROS, N. The European Geoparks Network: geological heritage protection and local development. Episodes, Lesvos, v. 27, n. 3, p. 165-171, 2004. 